\title{
Mobile Peer-Mentoring: An Approach to Make Veterans Seek Mental Health-Care Support a Normality
}

\author{
Rizwana Rizia, Nadiyah \\ Johnson, A. B. M. K. \\ Patwary, G. M. T. Ahsan, S. \\ I. Ahamed, \\ Ubicomp Lab, \\ Marquette University, WI, \\ USA \\ \{rizwana.rizia, \\ nadiyah.johnson, \\ abm.patwary, \\ golammushihtanimul.ahsan, \\ sheikh.ahamed\}@marquette. \\ edu
}

\author{
Zeno Franco \\ Medical College of \\ Wisconsin, Milwaukee, WI, \\ USA \\ $\{$ zfranco $\} @$ mcw.edu
}

\author{
Katinka Hooyer \\ University of Wisconsin- \\ Milwaukee, Milwaukee, \\ WI, USA \\ \{katinka\}@uwm.edu
}

\author{
Bob Curry, Mark Flower, \\ Dryhootch, Milwaukee, \\ WI, USA \\ \{bob,mark\}@dryhootch. \\ org
}

\begin{abstract}
Veterans often face great difficulties during the community and family reintegration after military deployment. Mental health problems resulting from war related traumatic experiences often make social readjustment very difficult. Many research suggests that peer-mentorship can be very effective for mental-health problems. Dryhootch (DH), a community organization led by veterans, has implemented a veteran peermentor program. The primary objective of $\mathrm{DH}$ program is to provide peer-mentor support to veterans going through social readjustment. In this paper we propose to expand DH's paperbased peer-mentor program with a mobile-based system, iPeer. The proposed expansion improves the efficiency of the current DH approach by augmenting the existing social process with mobile technologies used extensively by younger veterans returning from Afghanistan and Iraq. We provide a description of the evolution of this mobile-based peer-mentor support tool through collaborative design research. We also present our initial usability findings in order to demonstrate the improved efficiency offered by the augmented technology.
\end{abstract}

Keywords- Veteran mental healthcare; OEF/OIF veterans; mobile computing; symptom monitoring; electronic peermentorship; socio-technical systems; collaboration systems

\section{INTRODUCTION}

Many researches on post-war deployment health problems found that, traumatic combat experiences faced by veterans can have huge impact on community and family reintegration. The need for systematic service strategies for helping veterans go through this phase are considered to be crucial. Even though Department of Defense (DOD) and the Department of Veterans Affairs (VA) are dedicated in helping this population, they do not have enough reach into the communities where veterans reside. The need for community-based prevention model has been gaining focus recently. As a result a system, service or process for helping veterans with community based civilian reintegration is becoming a necessity [1].

Dryhootch(DH) is a veteran-led community organization. This organization provides informal network of peer-mentor support for helping veterans entering into civilian life. Each DH peer-mentor is a veteran, who has previously dealt with the difficulties of this re-adjustment phase. The current approach uses paper-based behavioral surveys to assess veterans. Each mentee meets their mentors to fill-in the surveys. The surveys are designed to illuminate the veteran's status on social functioning and risk taking actions. The mentors use the survey responses and their own judgment to understand the veteran's current mental-health status and its reflection on his or her activities.

Veterans trying to readjusting into community are often busy with re-entry into school and employment, rebuilding family life, recovering from health-related issues etc. [1]. Seeking services that primarily focuses on psychological well-being and sound mental health, are highly unlikely and often ignored unless the veteran is experiencing acute problems. Again, the manual paper-based approach makes it difficult for the peermentors to organize their mentees. Moreover, as there is no way to visualize conditions over broader time period, it is very difficult to identify and focus on mentees at high risk for behavioral or mental health difficulites. Lack of systematic administration and limitations of veteran peer-mentors, such as problems with judgment, attention, concentration, information processing etc., resulting from war-related conditions makes the paper based system very inefficient [3].

In this paper, we propose a mobile-based peer-mentor support system for veterans. The proposed system expands DH's current process with technology-based systems like - (1) A Mobile-based application for mentees to access those behavioral surveys remotely so that the process becomes ubiquitous, (2) A 
mobile-based application for veteran mentors that helps them visualize the condition of their mentees over broader time period (several weeks). The contribution of the proposed system can be outlined as, (1) The first mHealth approach for helping veterans in civilian reintegration with peer-mentor support, (2) Assisting veteran peer mentors to recognize and address veterans reintegration problems proactively; rather than after sentinel events such as- family breakdown or loss of employment etc., (3) Identifying mild-symptoms of mental-illness in its early stage and preventing it from becoming chronic.

We begin this article with a description of the common civilian reintegration problems faced by veterans. A review of related literature is presented next. We then describe the need for the technology-mediated peer-mentor process. The methods of the system design and development process are described in a following section. The next section contains our findings that supports our outlined contribution.

\section{DIFFICULTIES OF CIVILIAN REINTEGRATION}

Returning home after years spent at wars are not among the periods people face in their ordinary life. Because reintegration related stress can have huge impact and life-threatening consequences, the U. S. Army describes the reentry and reintegration problem to be as important as preparing soldiers for combat deployment [4]. Many research works studied the common problems faced by veterans during reintegration phase. Some of these results show that, $49 \%$ reported problems with community activity participation, $42 \%$ found it difficult to reunite with spouse and partners and $25 \%$ had difficulty with jobs. Other identified problems are difficulty in anger management, dangerous driving and legal issues [5].

Research on Vietnam veterans' civilian readjustment found that the higher the level of war related trauma and posttraumatic symptoms, the worse the family functioning and domestic violence than those without trauma [6]. Research on current service strategies found that $96 \%$ of veterans who received VA services expressed their interest in receiving services that may help reentry and reintegration into family and community life. Their preferred ways to receive services were identified as, services at a VA facility, through email or via internet communication [7].

\section{RELATED WORKS}

The ubiquitous mobile device, with its diverse capabilities is now a days the closest beloved technology to people. Mobilephones can response instantaneously at a moment of need, can track its owner's life, and prompt the owner to take action at the correct moment. These devices are great tool for documenting their owner's progress in their natural environment. They can be used for diagnosing conditions and managing both the physical and behavioral health [9]. Traditional mental-health care procedures take place in clinics. But social stigma associated with mental-illness, obstacles in continuation (e. g. financial conditions, need for time and motivation etc.) often result in discontinuation of clinic visit and treatment continuation. But mobile-devices are able to overcome these difficulties of mentalhealthcare treatments. These devices are capable of collecting and recording data in real-time [10]. They can be used for real- time repeated sampling of subject's current behavior and experience in his/her natural environment. As a result a good platform for conducting EMA (Ecological Momentary Assessments) on associated symptoms [11].

Because of this ubiquitous nature of mobile devices both DOD and VA have adopted mobile healthcare to expand clinical care beyond office visit [8]. VA has released a series of mobile healthcare application to better serve mental healthcare [16]. PTSD coach if one such application. By providing selfmanagement techniques, the app helps veterans at risk of PTSD [14]. Developed by DOD and VA, PE Coach is another app for supporting PTSD treatment. The app is used to support Prolonged Exposure (PE) psychotherapy sessions [15]. eCBT Trauma [17], PTSD Support [18], PTSD Eraser [19] are some other apps developed for veterans. All the mental healthcare apps developed under VA or DOD have their focus on PTSD management. But none of them have explored the use of this powerful technology for helping through the reintegration phase. Again, although powerful, the effectiveness of technologymediated peer-mentorship was never applied [12].

POS REP is a mobile app which has the same motivation as iPeer and has its focus on helping veterans in the civilian reintegration process. This app helps veterans stay connected with other veterans within their geographic area. The veterans can continue with the position report and communication strategy with other team members in the same way they used to do when operating in dangerous combat environments [13]. iPeer is different from POS REP with its dedicated peer-mentor support and by tracking the civilian reintegration progress in real-time.

\section{IDENTIFYING NEEDS}

Even though DH has been working on helping veterans with peer-mentor support through the re-entry phase, their process failed to meet the need of the younger veteran population on university and technical school-campus. This set of population has some specific needs, such as, first, they need the service hours to be available after normal business hours. Second, they are more comfortable with modern communication mediums, such as smartphone apps, computers, social media etc. The other identified needs for using technology-based services are described in the following two sub-sections.

\section{A. Issues with Efficiency and Scalability}

Veterans are often busy dealing with family, employment and other community readjustment problems. Most of the time they seek very low motivation to continue with services that are purely mental-health oriented. In order to continue with the DH services, the veterans need to schedule appointments with their mentors regularly and visit to fill-in the surveys. Clearly, they need to adjust time from their regular activity and still they do not see any obvious results that may motivate them. The mHealth approach may make this process ubiquitous and integrate it with their daily life activity. As a result, they can have a quick check-in with their mentors without timing delays and adjustment schedules. 


\section{B. Problems with Manual Approach}

The current $\mathrm{DH}$ approach puts a lot of load on the veteran mentors. They need to have an in-detail review of each of the survey responses from their mentees. Moreover they need to use their own judgment to understand the overall mental-health condition. When the number of mentees are large, the process is overwhelming for the mentors. No automatic process is available there to help with report generation, visual presentation of status and managing mentees.

\section{DESIGN AND DEVELOPMENT METHODS}

Designing a technology-based intervention for mental healthcare has been identified as a very challenging task by many research [20]. The iPeer system needed to be designed for veterans. This population is considered to be dealing with many veteran specific psychological issues. Low frustration tolerance, anxiety, and lack of patience are few such conditions [3]. While developing a system for this at risk population we also dealt with those challenges. Our design and development process went through two critical phases. The early stage design process was conducted only by development and research team and the later stage included veterans in the design process.

\section{A. Initial Design Phase and Lessons Learned}

The initial design phase followed a traditional software design and development approach. The research team (included community engagement specialists [CESs] and Social Scientists [SSs]) collected initial requirements from $\mathrm{DH}$ veteran mentors. The CES translated the requirements to development team. The development team designed the system based on CES's assumption on the peer-mentor process. Fig. 1 shows the initial architecture.

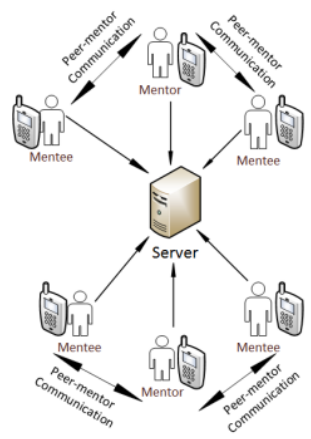

Figure 1. iPeer System Overview

The initial system used two software. One for mentors and the other for mentees. The mentees receive surveys on their phones and submit responses to the server. The mentors can view the responses of their mentees on their phones. The system was then deployed among the veterans and their mentors on University of Wisconsin-Milwaukee campus, but the initial deployment failed with the following issues.

\section{1) Lack of Human Driven Process}

The veteran mentees complained about the survey submission process. A human driven actual peer-mentorship was missing within the system. "We don't want the veterans to feel like, they are just submitting the surveys for some research. They need the comfort of actual peer-mentorship" - one veteran mentor. The key lesson we derived from here is, the peer-mentorship helps the veteran share their unique feelings and fears with someone who has previously dealt with these emotions. The technologybased system should also give them the same sense of personalized care and attention.

2) Lack of Veteran Problem Focus

One of the veteran mentor complained that the system was not working on her phone. After investigation the development team found that her phone was an older device and the software showed errors on it. She was requested to switch to a newer device. However, she preferred to use her own device as it had keypad. Anxiety related issues make her hand sweat and she cannot use touchscreen. The key lesson we derived from here is, the design elements into the system should consider needs, strengths and limitations of veterans, as they are the primary user of the system.

\section{3) Lack of Trust among Veterans and Design Team}

Many veterans have deep suspicion about government services and government policies for veterans. They fear if someone reveals their personal weaknesses, government may cut their benefits [21]. Again, long wait lists in government service centers, internal priority lists etc. made it very hard for them to trust anyone [22]. Involving veterans in the design process seemed like a must in order to establish trust in the final mobile app itself.

\section{B. Collaborative Design Phase}

After analyzing the initial design phase and lessons from it, the research team realized that a collaborative design process is a crucial requirement in order to reduce gap in understanding the process requirements. The iPeer project involved stakeholders with different expertise. This helped us to adopt a Community Collaborative Design Process [Fig. 2(c)]. Our collaborative design team included veteran mentors (VM) from DH, CESs, SSs and system development team. VMs brought end-user's perspective in design decision making. This method merges with the current shift in design methods from an object perspective to a human needs perspective [23]. A human needs perspective prioritizes socio-cultural responsibility and commitment to improving the lives of the end users. It requires a keen sensitivity to cultural differences and how these differences play out in the acceptance and adoption of a new product [24]. We further rooted our collaborative process in a synthesis of participatory action research (where users take part in the development of a product) [2] and design anthropology (a methodology that focuses on the mutual influence of culture and design) [25]. Findings of these collaborative design are listed below.

1) Emulate the human Driven Process

"I check-in with my mentees on a regular basis. They visit and completes the survey and we discuss their activities throughout the past week" - says one of the veteran mentor, in response to the question of how the peer-mentor ship works currently. This gave the design team the idea to implement a quick check-in process for survey submission [Fig. 3 (b)].

2) Collaborative Design Increased Trust 
During the collaborative design process, the veteran mentors actively participated during design decision making. They were able to test the system instantly and provide feedback verbally. White board sketches were used to give them a visual representation of the final application screens [Fig. 2(a) and 2(b)]. They even participated in drawing those sketches and choosing items for system elements. This process of designdevelopment-assessment-design loop developed a trust among veteran community and the research team. The veteran mentors were able to see they are actually taking the design decisions and the others valued their needs.

\section{System Components}

The final system had two main modules: Mentor's Module (iPeerMentor) and Mentee's Module (iPeerVeteran).

\section{1) iPeerVeteran}

This is the software for the mentees. The mentees receive two surveys during the week. One survey is available from MondayTuesday and the other survey is available from FridaySaturday. The surveys are available in form of a check-in. A button labeled check-in appears for each survey availability [Fig. 3(b)]. The check-in process was incorporated to complement the human driven peer-mentorship. When a mentee clicks an available check-in, he or she will get the questions for the surveys. The process emulates a mentee's checking-in process with their mentor.

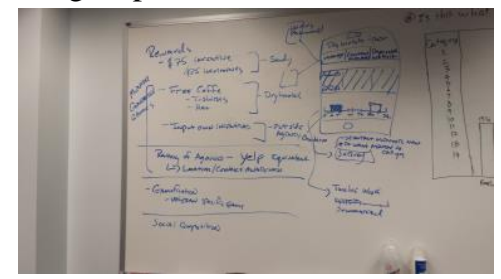

(a)

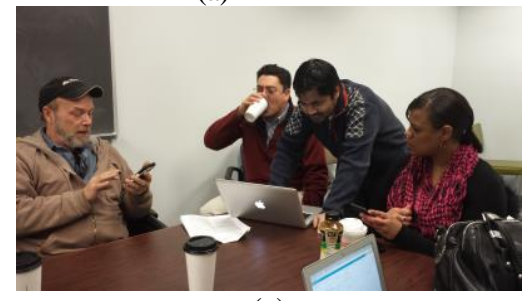

(c)

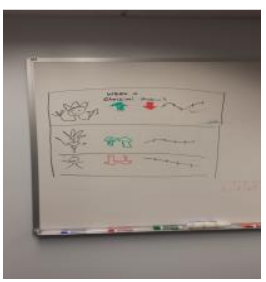

(b)
Figure 2. (a)White Board Sketches of Check-in Process, (b) White Board Sketches of Mentee List and (c) Veteran Mentors Testing the System during Design Meeting

\section{2) iPeerMentor}

This software is used by the mentors. When the mentors login they get a screen that contains a list of all their mentees. Each mentee on the list, consists of an identifying picture, two icons representing the survey responses for the current week, and a graphical view representing the status of the survey responses over a broader time period [Fig. 3(a)]. The icons for the current week can have either a red-thumbs-down or a green-thumbs-up. A red-thumbs-down represents a missed survey or a negative result or worse condition. A green-thumbs-up represents a positive result or improved condition.

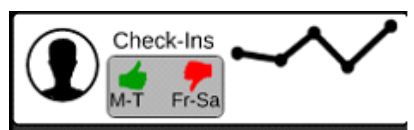

(a)

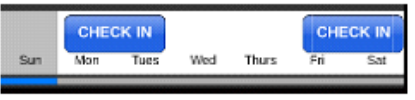

(b)
Figure 3. (a) Mentee Representation on Mentor App and (b) Check-in Process in Mentee app

\section{FINDINGS}

The collaborative design phase gave the research team an opportunity to analyze the two processes, paper-based peermentoring and mobile-based peer-mentoring. The analysis was based on the feedbacks from the veteran mentors, CESs and SSs. In the following subsections we will discuss the key findings.

\section{A. Ubiquitous Process}

"Heather always finds herself trying to manage schedule for her mentees. But her schedules were all full. She mentors 16 mentees. It is very hard for her to find time for each of them. Sometimes few of them miss visits and surveys just because of this problems with communication. Once the mobile-based system is deployed, the whole process will become easy for her. Now she will never have to visit each of her mentees just to get the survey responses. She can easily find their responses with the mobile device." - This scenario clearly shows how the mobile-based system made the process ubiquitous. This is also true for the mentees. With this mobile-based app they can access surveys from anywhere and check-in with their mentor without interrupting their daily activity.

\section{B. Reduced Mentor Workload}

The mobile app gives the mentors easy interface to add mentees and manage and organize their records. An easy accessible listview is available to see which of their mentees need special attention. Because of the graphical interface, they don't have to go over each survey responses in order to understand their mentees' status. The mobile app now computes the overall status and shows them an easy understandable display [see Figure 3(a)].

\section{Making Mental HealthCare a Normal Standard}

Veterans going through social re-entry phase have very low motivation to focus on services that are purely mental-health oriented. They have high priority tasks of family and employment readjustment. A mobile-based peer-mentor approach allows easy sharing of present status through behavioral surveys. The process can be accomplished remotely and even after normal business-hours. As a result, even the service is focusing completely on mental wellness, it does not require a great effort to continue. As a result, veterans seeking mental-healthcare can become a routine part of daily life during civilian reintegration.

\section{Early Detection of Mental-illness}

The mobile-based peer-mentoring improves the efficiency of the mentoring process. The mentors can easily monitor their mentees status and the mentees can easily continue with the service. The graphical representation of behavioral data and the 
status icons for the current week helps in understanding any negativity in mental-health condition at a very early stage. As a result, early intervention or support is facilitated.

\section{E. Improved Data Quality}

With the paper-based approach, the survey responses from veterans are often biased by memory recall issues. The mobilebased approach is facilitating real-time data collection within their natural environment. As a result the quality of data represented to the mentors is greatly improved.

\section{CONCLUSION}

In this paper we presented the design, development and deployment of a mobile-based peer-mentor support system for veterans reintegrating into civilian community. We also described the usability findings derived from the feedback of the veteran mentors. The system was deployed among student veterans on University of Wisconsin-Milwaukee campus. In the future we plan to analyze the result of this deployment to find its impact on civilian reintegration.

\section{ACKNOWLEDGMENT}

This project is funded wholly by the Healthier Wisconsin Partnership Program (HWPP), a component of the Advancing a Healthier Wisconsin endowment at the Medical College of Wisconsin.

\section{REFERENCES}

[1] M. C. Harrell, and N. Berglass, "Well After Service: Veteran Reintegration and American Communities". Report for Center for a New American Security (CNAS), 2012.

[2] F. Kensing, and J. Blomberg, "Participatory Design: Issues and Concerns". Journal of Computer Supported Cooperative Work (CSCW), 1998, Volume 7, Issue 3-4, Page 167-185

[3] T. E. Church. "Returning Veterans on Campus with War Related Injuries and the Long Road Back Home". Journal of Postsecondary Education and Disability, 2009, Version 22, Issue 1, Pages 43-52.

[4] M. E. Doyle, and K. A. Peterson, "Re-Entry and Reintegration: Returning Home after Combat". Journal of Psychiatric Quarterly, December 2005, Volume 76, Issue 4 Pages 361-370.

[5] L. Resnik, D. W. Bradford , S. M. Glynn , A. M. Jette, C. J. Hernandez and S. Wills, "Issues in defining and measuring veteran community reintegration". Proceedings of the Working Group on Community Reintegration, VA Rehabilitation Outcomes Conference, 2012, Volume 49, Pages $87-100$.

[6] S. L. Sayers, V. A. Farrow, J. Ross and D. W. Oslin, "Family problems among recently returned military veterans referred for a mental health evaluation". Journal of Clinical Psychiatry, February 2009, Volume 70, Issue 2, Pages $163-170$.

[7] N. A. Sayer, S. Noorbaloochi, P. Frazier, K. Carlson, A. Gravely and M. Murdoch, "Reintegration Problems and Treatment Interests Among Iraq and Afghanistan Combat Veterans Receiving VA Medical Care". Journal of Psychiatric Services, 2010, Volume 61, Pages 589-97.

[8] U. S. Department of Veteran Affairs, "VA Mobile Health". [Online]. Available: https://mobilehealth.va.gov/

[9] M. Tentori, G. R. Hayes, and M. Reddy, "Pervasive Computing for Hospital, Chronic, and Preventive Care". Journal of Foundations and Trends in Human-Computer Interaction, January 2012, Vol. 5, Issue 1, Pages 1-95.
[10] R.R. Fletcher, S. Tam, O. Omojola, R. Redemske, S. Fedor and J.M Moshoka, "Mobile Application and Wearable Sensors for Use in Cognitive Behavioral Therapy for Drug Addiction and PTSD”. 2011 5th International Conference on Pervasive Computing Technologies for Healthcare (PervasiveHealth), May 2011, Pages 202-203.

[11] S. Shiffman, A. A. Stone and M. R. Hufford, "Ecological Momentary Assessment. Annual Review of Clinical Psychology", November 2007, Volume 4, Pages 1-32.

[12] C. Shpigelman, P. L. Weiss and S. Reiter, "E-Mentoring for All". Journal of Computers in Human Behavior, July 2009, Volume 25, Issue 4, Pages 919-928.

[13] [30] POS-REP - A Social Network for the $0.5 \%$. Retrieved on 12 March 2014. [Online] Available: http://pos-rep.com/

[14] [24] Support for PTSD: PTSD app at Real Warriors. n. p., n. d. [Online]. Available: http://www.realwarriors.net/active/treatment/ptsdcoach.php

[15] 15. PTSD Support App - Mobile Health Marketplace. The leading directory of mobile health apps and devices, n. p., n. d. [Online]. Available: http://www.mobilehealthmarketplace.com/listings/pe-coachptsd-support-app/

[16] Pai, A. "15 apps from the Department of Veterans Affairs" 11 Nov 2013. MobiHealthnews. Retrieved on Retrieved on 12 March 2014 [Online]. Available: http://mobihealthnews.com/27237/15-apps-from-thedepartment-of-veterans-affairs/

[17] 17. Grohol, J. M. (2010). MindApps Releases eCBT Trauma. Psych Central. Retrieved on March 12, 2014, [Online]. Available: http://psychcentral.com/blog/archives/2010/02/16/mindapps-releasesecbt-trauma/

[18] 18. "PTSD Support by Mobile Roadie" PTSD Support on the App Store on iTunes. 04 Dec 2013 . Apple App Store. Retrieved on 12 March 2014 [Online]. Available: https://itunes.apple.com/us/app/ptsdsupport $/ \mathrm{id} 379160810 ? \mathrm{mt}=8$

[19] 19. Stein, Traci. "Free Apps for Relaxation, De-Stressing \& PTS" 18 March 2013 . healthjourneys. Retrieved on 12 March 2014 [Online]. Available: http://www.belleruthnaparstek.com/update-from-belleruth/aspate-of-free-apps-for-relaxation-de-stressing-pts.html

[20] [32] D. Coyle and G. Doherty, "Clinical evaluations and collaborative design: developing new technologies for mental healthcare interventions". Proceedings of the SIGCHI Conference on Human Factors in Computing Systems, 2009, Pages 2051-2060.

[21] [41] N. Offen, E. A. Smith and R. E. Malone, "Willful misconduct": how the US government prevented tobacco-disabled veterans from obtaining disability pensions. Am J Public Health. 2010 July; Vol. 100, Issue7, Pages 1166-1173.

[22] Wagner, D. Acting VA Secretary Gibson says 18 vets on Phoenix wait list died, The Republic, Retrieved on June 2014 [Online] Available: http://www.azcentral.com/story/news/arizona/investigations/2014/06/05/ va-scandal-sloan-gibson-phoenix/10023845/

[23] H. Christiaans, and J. Diehl, "THE NECESSITY OF DESIGN RESEARCH INTO CULTURAL ASPECTS". Proceedings International Association of Societies of Design Research, Hong Kong Polytechnic University, 2007.

[24] H. Christiaans and J. C. Diehl, (2006). "The importance of studying cultural diversity regarding product usability". In: R.N. Pikaar, E.A.P. Koningsveld, and P.J.M. Settels, eds. Proceedings IEA2006 Congress. Elsevier Ltd, (2006).

[25] A.J. Clarke (Ed). "Design Anthropology: Object culture in the 21st century”. Springer-Verlag: Vienna, Austria, 2011.

[26] Z. Franco, M. Flower, B. Curry, J. Whittle, K. Berte. "Surviving the peace: redefining community based veteran services through the DryHootch partnership". The Praeger handbook of social justice and psychology: Vol. 2. Well-being and professional issues. Santa Barbara, CA: Praeger; In press. 